\title{
Characterization of Telomerase (hTERT) in Solid and Hematopoietic Cancer Cell Lines Reveals Different Expression Patterns
}

\author{
LUCAS SILVA DE HOLANDA ${ }^{1}$, FELIPE PANTOJA MESQUITA ${ }^{2}$, MANOEL ODORICO DE MORAES-FILHO ${ }^{2}$, \\ MARIA ELISABETE AMARAL DE MORAES ${ }^{2}$, RAQUEL CARVALHO MONTENEGRO ${ }^{2}$, \\ ADRHYANN JULLYANNE DE SOUSA PORTILHO ${ }^{2}$ and CAROLINE AQUINO MOREIRA-NUNES ${ }^{1,2}$ \\ ${ }^{1}$ Unichristus University Center, Faculty of Biomedicine, Fortaleza, Brazil; \\ ${ }^{2}$ Pharmacogenetics Laboratory, Drug Research and Development Center (NPDM), \\ Department of Physiology and Pharmacology, Federal University of Ceará, Fortaleza, Brazil
}

\begin{abstract}
Background/aim: Overexpression of human telomerase reverse transcriptase ( $h T E R T$ ) allows disordered proliferation and immortality of malignant cells, which has been of interest for the development of targeted therapies. The present study aimed to characterize hTERT gene expression in a series of cancer cell lines. Materials and Methods: Leukemia cell lines $K-562$, its vincristine-resistant derivative $K$-562-Lucenal and daunorubicin-resistant derivative FEPS; gastric adenocarcinoma lines AGP01, ACPO2 and ACPO3; melanoma SK-Mel-103 cells; and MNO1 and MRC5, two nonneoplastic cell lines were analyzed by real-time polymerase chain reaction in order to evaluate hTERT gene expression. Results: In leukemia cells, hTERT gene expression was significantly increased only in K-562 $(p<0.05)$ and $K-562$ Lucenal $(p<0.001)$ when compared to the calibrator MRC5. For solid tumor types, only ACP03 presented a significant hTERT gene expression when compared to ACP02 $(p<0.05)$. hTERT gene expression in $K-562$ and $K-562-L$ ucena was significantly increased $(p<0.05$ to $p<0.001)$ compared to all other cell lines except ACP03. Conclusion: In leukemia cell lines, hTERT gene overexpression was shown to be a potential target for pharmacological assays for drugs aiming to inhibit telomerase activity and control cell proliferation in oncohematological diseases.
\end{abstract}

Cancer cells have properties that maintain them in sustained proliferative activity, with a striking pattern known as

Correspondence to: Caroline Aquino Moreira-Nunes, Federal University of Fortaleza, Coronel Nunes de Melo st, n 1000, Rodolfo Teófilo, CEP: 60416-000 Fortaleza, CE, Brazil. E-mail: carolfam@gmail.com

Key Words: Cancer, telomerase, cell lines, gene expression, hTERT. replicative immortality, which is one of the most important characteristics and problems in the fight against these cells in the organism of affected species. Therefore, the ability of cells to replicate in a disorderly way and not undergo senescence has been shown by tumor models to be due to telomerase overexpression (1).

Human telomerase reverse transcriptase (hTERT) is an enzyme responsible for the maintenance of chromosomal ends and, in turn, protects DNA from degradation, being expressed in about $85 \%$ of cancer cells and poorly expressed in healthy cells (2-5).

Inactivation or inhibition of the $h T E R T$ gene has been used as a means of restraining the replication of neoplastic cells. In this context, the expression of telomerase in most types of cancer cells has attracted the interest of studies towards development of targeted therapies $(6,7)$.

Experimental oncology is a branch of science that uses established human cell lines with original genetic and morphological characteristics of the tissue of origin as tools for understanding the biology and molecular pathways (genetic and epigenetic) of different tumor types for the subsequent development of new therapies in order to characterize malignant tumor patterns in basic research. In order for these studies to be increasingly objective and illuminating, the characterization of these cell lines is necessary, especially for the most important purpose of experimental oncology, which is the development of new antineoplastic drugs, in addition to understanding the mechanisms of action of and resistance or sensitivity to new chemotherapeutics and those already used in the treatment of cancer (8-10).

However, studies point to variation in gene expression between the same cell lines grown in different laboratories. It has been suggested that the variation is caused by epigenetic mechanisms, such as methylation, and due to 
Table I. Cell lines evaluated in this study.

\begin{tabular}{lccc}
\hline Cell line & Tissue of origin & Classification & Reference \\
\hline AGP01 & Ascitic fluid of gastric adenocarcinoma & Intestinal & Diffuse \\
ACP02 & Gastric antrum adenocarcinoma & Intestinal & 14 \\
ACP03 & Gastric cardia adenocarcinoma & NA & 14 \\
SKMel-103 & Melanocyte & Normal cells & 14 \\
MN01 & Non-neoplastic gastric epithelium & NA & 16 \\
K-562 & Bone marrow chronic myeloid leukemia & Vincristine-resistant & 17 \\
K562-Lucena1 & Derived from K-562 & Daunorubicin-resistant \\
FEPS & Derived from K-562 & Normal cells \\
MRC-5 & Human fetal lung fibroblasts & 13 \\
\hline
\end{tabular}

NA: Not applicable.

different culture conditions from one laboratory to another, and variation in the gene expression of these lines modifies the original morphology and proliferation $(10,11)$.

The aim of this study was to characterize hTERT gene expression in a panel of tumor cell lines usually used in experimental oncology in order to validate the models as potential screening tools for target-directed therapies against telomerase activity in cancer.

\section{Materials and Methods}

Cell culture. For the evaluation of hTERT gene expression, a panel of experimental oncology lines was used. The chronic myeloid leukemia cell lines K-562, vincristine-resistant derivative K-562Lucena1, and daunorubicin-resistant derivative FEPS were kindly provided by Professor Vivian M. Rumjanek from Federal University of Rio de Janeiro, Brazil $(12,13)$ and maintained in RPMI medium. The K-562-Lucenal and FEPS cell lines were maintained with RPMI medium supplemented with $60 \mathrm{nM}$ vincristine sulphate and $46 \mathrm{nM}$ daunorubicin, respectively. The gastric adenocarcinoma cell lines AGP01, ACP02 and ACP03; melanoma cell line SK-Mel-103; and two non-tumoral cell lineages from gastric epithelium (MN01) and lung fibroblast (MRC-5) were maintained in Dulbecco's modified Eagle's medium. All cell lines were maintained in media with specific supplements and incubated with $5 \% \mathrm{CO}_{2}$ at $37^{\circ} \mathrm{C}$ (Table I).

Extraction of RNA and reverse transcription of RNA to DNA. RNA from all cell lines was extracted with TRIzol Reagent ${ }^{\circledR}$ (Invitrogen ${ }^{\mathrm{TM}}$ ) according to the manufacturer's instructions. From $20 \mathrm{ng}$ of RNA, the cDNA was synthesized using High Capacity cDNA Reverse Transcriptase kit (Life Technologies, Carlsbad, CA, USA) to convert the extracted and purified RNA to cDNA. The conversion step was performed on a Veriti ${ }^{\circledR}$ thermal cycler (Applied Biosystems ${ }^{\circledR}$, Foster City, CA, USA). After this step, the samples were stored in a freezer at $-20^{\circ} \mathrm{C}$ until use for analysis.

Validation of gene expression by real-time quantitative polymerase chain reaction $(q P C R)$. The gene selected for evaluation of telomerase expression was hTERT (Hs_00972650_m1), and the gene GAPDH (Hs02786624_g1) was used as an internal control.
The detection method was the TaqMan ${ }^{\circledR}$ Gene expression assays system (Applied Biosystems and qPCR was performed using QuantStudio5 Real-Time PCR system (Applied Biosystems For each sample, the following were used: $3 \mu \mathrm{l}$ of cDNA, $1 \mu \mathrm{l}$ of each primer/probe, $12.5 \mu \mathrm{l}$ of TaqMan ${ }^{\circledR}$ Gene Expression Master Mix (Life Technologies, Carlsbad, CA, USA) and $8.5 \mu \mathrm{I}$ of ultra-pure water. The gene-expression levels were based on absolute and relative analyses and calculated using the $2^{-\Delta \Delta C T}$ (delta delta threshold cycle) method (19) using the MRC-5 cell line as the calibrator/control. Each sample was analyzed in triplicate for the validation of the technique and the values of $\mathrm{CT}$, according to the international standards for evaluation of gene expression by realtime PCR (20).

Statistical analysis. Analysis of one-way variance (ANOVA) was used to analyze gene-expression data, with an acceptable significance level of $5 \%(p<0.05)$. Test data were analyzed from the mean and standard deviation of three independent experiments. The Bonferroni correction method was used for multiple comparisons.

\section{Results}

In the comparative analysis of leukemia cell lines, $h T E R T$ gene expression of the K-562 strain was significantly increased compared to that of MRC-5 $(p<0.05)$, as it was in $\mathrm{K}-562$-Lucena1 cell line $(p<0.001)$. However, in this analysis, there was no statistical significance $(\mathrm{p}>0.05)$ in the difference of expression of $h T E R T$ in FEPS compared to the calibrator MRC-5. Leukemia cell lines K-562, K-562Lucena1 and FEPS, when compared among themselves, did not differ statistically significantly (Figure 1).

Regarding comparative analysis of the gastric adenocarcinoma, melanoma and normal gastric epithelial cell lines with MRC-5, the results showed that there was only significant expression of hTERT in the ACP03 cell line $(p<0.05)$, and that expression of hTERT in ACP03 was significantly greater when compared with ACP02 $(p<0.05)$ (Figure 2). Our results also show that the MN01 normal gastric epithelial cells had similar expression of $h T E R T$ gene to the AGP01 and ACP02 gastric adenocarcinoma cell lines. 


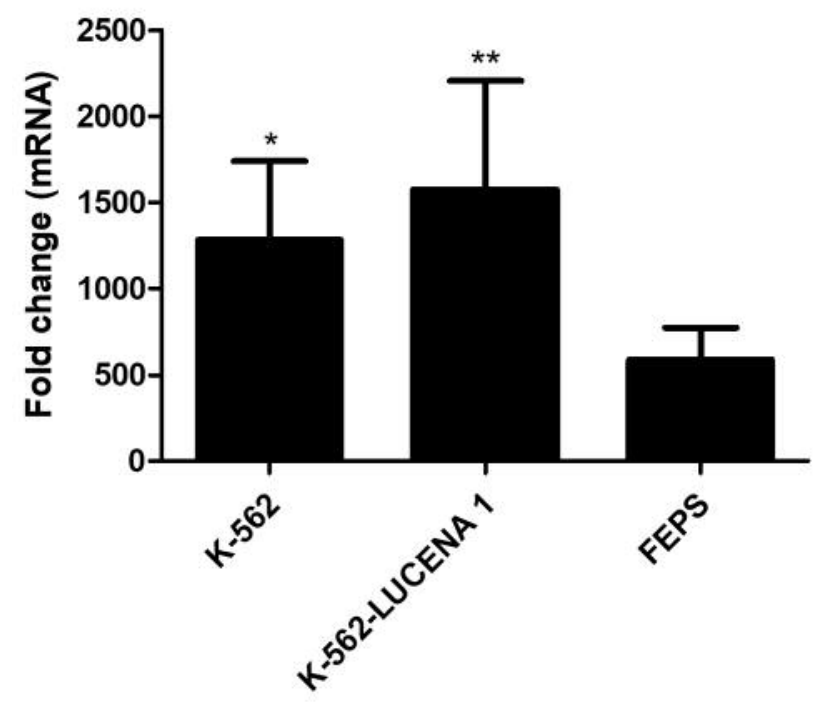

Figure 1. Evaluation of human telomerase reverse transcriptase (hTERT) gene expression in leukemia cell lines. Fold change data are represented as mean \pm standard deviation of three independent experiments. hTERT gene expression was compared between leukemia cell line $K-562$, its vincristine-resistant derivative $K-562-L u c e n a 1$, daunorubicin-resistant derivative FEPS, relative to that in MRC-5 lung fibroblasts, using ANOVA statistical test and multiple Bonferroni comparisons. Significantly different compared to FEPS at $* p<0.05$ and ${ }^{* *} p<0.001$.

Finally, we compared $h T E R T$ gene expression between all the cell lines. Our results show K-562 cells to have significantly higher $h T E R T$ expression in relation to MN01 $(p<0.05)$, AGP01 $(p<0.05)$, ACP02 $(p<0.001)$ and SK-Mel$103(p<0.05)$ cells. The K-562-Lucena1 cell line presented significantly higher gene expression in relation to MN01 $(p<0.001)$, AGP01 $(p<0.001)$, ACP02 $(p<0.001)$ and SKMel-103 $(p<0.001)$ cells (Figure 3$)$.

\section{Discussion}

In differentiated human cells, telomerase is silenced due to inhibition of the hTERT gene. However, in malignancies, telomerase is highly activated, being essential during oncogenesis for stabilizing telomere length and in order to confer replicative immortality capacity on the cell, as well as confer resistance to chemotherapy and radiotherapy (20).

Mutations in the promoter of the hTERT gene are considered the most common genetic alterations in various types of cancer (21-23). On the other hand, there are tumor types that not have a high frequency of mutations in the promoter region of this gene. In this context, telomerase has attracted the interest of studies that involve the inactivation or inhibition of its activity, as a means of restricting cellular proliferation in cancer, inducing the re-entry of the cell into

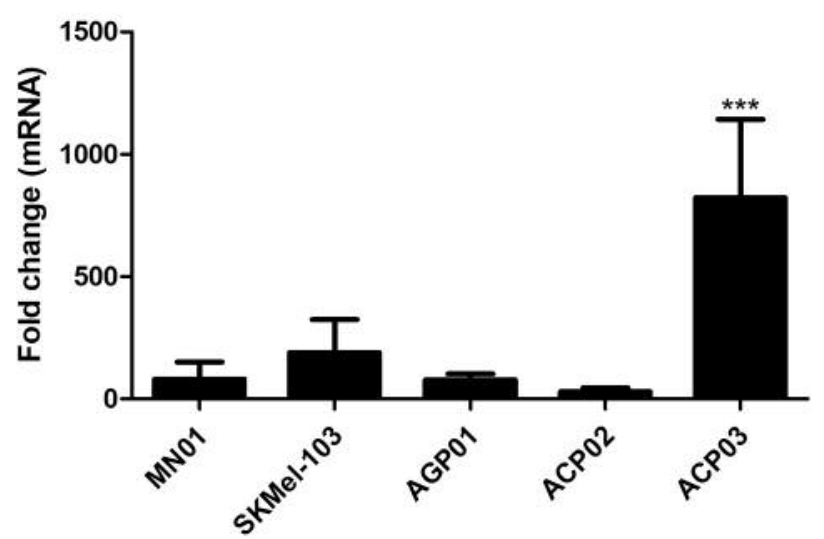

Figure 2. Evaluation of human telomerase reverse transcriptase (hTERT) gene expression in solid tumor cell lines: gastric adenocarcinoma (AGP01, ACP02, ACP03), melanoma (SKMel-103) and non-tumoral gastric mucosal (MNO1) cells. Fold change data are represented as mean \pm standard deviation of three independent experiments. Comparison of hTERT gene expression between gastric adenocarcinoma, normal gastric epithelial cells relative to that in MRC-5 lung fibroblasts was made using ANOVA statistical test and multiple Bonferroni comparisons. ***Significantly different compared to all other cell lines at $p<0.001$.

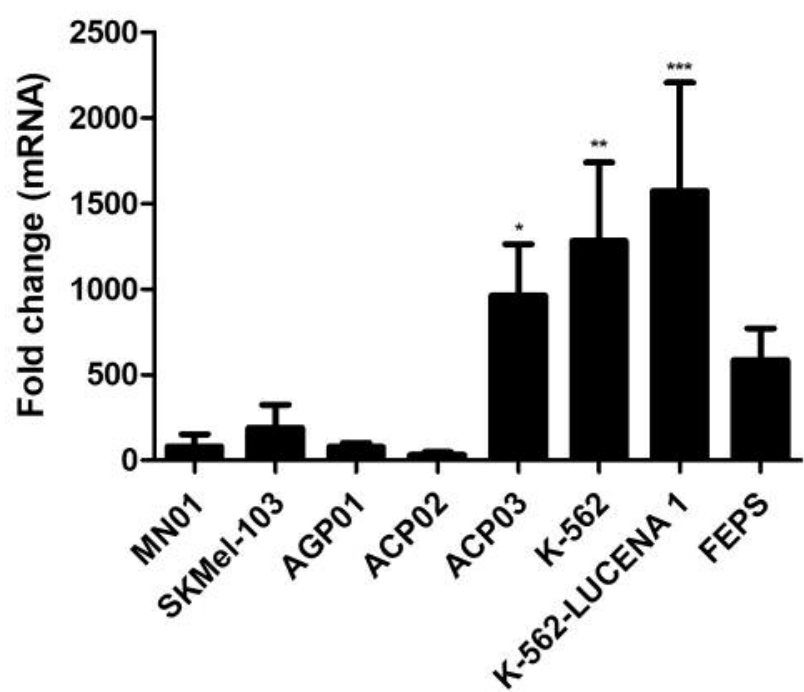

Figure 3. Comparison of human telomerase reverse transcriptase (hTERT) expression between leukemic cell lines (K-562, vincristineresistant derivative $K$-562-Lucena1, and daunorubicin-resistant derivative FEPS), gastric adenocarcinoma, (AGP01, АCP02, ACP03), melanoma (SKMel-103) and non-tumoral gastric mucosal (MNO1) cells. Fold change data are represented as mean \pm standard deviation of three independent experiments. Comparison of hTERT gene expression was made using ANOVA statistical test and multiple Bonferroni comparisons. Significantly different at $* p<0.05,{ }^{*} p<0.001$ and $* * * p<0.0001$ when compared to normal cell line MRC5. 
the normal cell cycle and, consequently, leading to programmed cell death, known as apoptosis $(3,7,24,25)$.

hTERT overexpression in K-562 and K-562-Lucena1 cell lines may be related to mutations in the promoter of the gene as shown in the study of Lansdorp et al. (26), who describes that $h T E R T$ amplification may also be seen as a cellular response to a decrease in telomeres size, considering that they tend to decrease in size in leukemia. Literature also shows that telomeres are shorter in leukemia cells with cytogenetic alterations, and shortening of telomeres is an important marker of cell malignancy (27-29). Therefore, shortening of the ends of the hematopoietic cell chromosomes may increase the chance of translocations and chromosomal loss, leading to genomic instability and cytogenetic changes (28).

With regards to the results for the AGP01, ACP02, ACP03, MN01, SK-Mel-103 and MRC-5 cell lines, it was noted that ACP03, an intestinal gastric cancer type according to the Lauren classification, had high hTERT expression compared with the ACP02 diffuse-type cell line $(p<0.05)$. In a study by Choi et al., patients with gastric cancer who had neoplastic diffuse cells had shorter telomeres, while patients with neoplastic intestinal lesions did not present telomere shortening. The authors further point out that a polymorphism in the $h T E R T$ gene may increase gene expression in intestinallike cells (30). Therefore, we suggest that the differentiaI expression of $h T E R T$ in the ACP03 cell line may be related to a polymorphism in the coding region of the gene.

Gastric cancer of the diffuse type has a worse prognosis when compared to the intestinal type (30). The prognosis of patients with gastric cancer can be determined by tumor size and diameter (31). Altered expression of hTERT in gastric adenocarcinoma cells contributes to the invasive and metastatic potential of these cells $(32,33)$. In this context, overexpression of $h T E R T$ in the ACP03 cell line may allow the cell to be more capable of tissue invasion, giving it the characteristic of greater aggressiveness when compared to the other gastric adenocarcinoma cell lines.

It is important to emphasize that the microenvironment in which a cancer cell is found is an important factor in the positive or negative regulation of this gene. According to Wang et al., the high expression of the hTERT gene in gastric adenocarcinoma may be related to physiological factors, such as acidification of bile acid, which induce hyperexpression of telomerase through the activation of the MYC gene, promoting tumor progression $(34,35)$.

When evaluating the expression of hTERT in the melanoma cell line SK-Mel-103, there was no statistical difference compared to the other strains, including that of normal gastric epithelium (MN01). Vicecont et al. showed that some melanoma cell line, do not express hTERT but, when it expressed, this is related to mutations in the promoter region of the gene (36).
When we compared all the cell lines used in this study, the leukemia lines (K-562 and K-562-Lucena1) showed high expression of the $h T E R T$ gene in comparison to gastric adenocarcinoma (AGP01, ACP02), melanoma (SK-Mel-103) and the normal gastric epithelial (MN01) cell lines. These results can be explained by the stimulus for telomerase expression that leukemia cells receive in order to compensate the shortening of the telomeres present in this type of cancer. Chromosomal translocations caused by shortening of the telomeres promote an increase in the expression of $h T E R T$ gene, and these phenomena are described in leukemia and other oncohematological diseases $(26-28,37)$, while in gastric adenocarcinoma and melanoma, point mutations or polymorphisms are main factors that increase hTERT gene expression $(30,36)$.

Zhang et al. found telomerase activity to be associated with cell lineage differentiation: the lower the telomerase activity, the more differentiated was the cell lineage; and the more differentiated, the lower was the replicative capacity of the cell (7). Based on this, the K-562 and K-562-Lucena1 cell lines would be expected to have a larger replicative capacity than AGP01, ACP02, SK-Mel-103 and MN01 because of their high expression of hTERT.

Finally, expression of $h T E R T$ may have be affected by changes in splicing of the $h T E R T$ gene $(38,39)$. In addition, there is the possibility that the hTERT gene has functions independent of maintenance of telomeres (26).

\section{Conclusion}

The overerexpression of hTERT in leukemia cell lines, compared to solid tumor cell lines, indicates that, in these cell lines, hTERT may be a target for pharmacological assays aiming to inhibit telomerase activity and control cell proliferation in oncohematological diseases. The tumor type of origin of the ACP03 line, by overexpressing hTERT, may be highly invasive and aggressive, and this cell line might also be useful in pharmacological trials of telomerasetargeting therapies. However, studies measuring the size of telomeres are necessary to understand the relationship of hTERT expression with the maintenance of telomeres in the studied cell lines.

\section{Conflicts of Interest}

The Authors declare no conflicts of interest regarding this study.

\section{Author's Contributions}

Moreira-Nunes CA, Mesquita FP, Portilho AJS and Montenegro RC performed the study design; Holanda LS and Portilho AJS performed the cell culture analysis; Holanda LS, Mesquita FP, Portilho AJS and Moreira-Nunes CA performed the molecular and statistical analyses; Holanda LS, Moraes-Filho MO, Moraes MEA, 
Montenegro RC and Moreira-Nunes CA wrote the article. All Authors read and approved the final article.

\section{Acknowledgements}

This study was supported by Brazilian funding agencies National Counsel of Technological and Scientific Development (CNPq; to CAMN, RCM, MEAM, MOMF and FPM) and Coordination for the Improvement of Higher Education Personnel (CAPES; to CAMN and AJSP).

\section{References}

1 Hanahan D and Weinberg RA: Hallmarks of cancer: The next generation. Cell 144: 646-674, 2011. PMID: 21376230. DOI: 10.1016/j.cell.2011.02.013

2 Alnafakh RAA, Adishesh M, Button L, Saretzki G and Hapangama DK: Telomerase and telomeres in endometrial cancer. Front Oncol 9: 344, 2019. PMID: 31157162. DOI: 10.3389 /fonc. 2019.00344

3 Ivancich M, Schrank Z, Wojdyla L, Leviskas B, Kuckovic A, Sanjali A and Puri N: Treating cancer by targeting telomeres and telomerase. Antioxidants 6: 15, 2017. PMID: 28218725. DOI: 10.3390/antiox6010015

4 Biray Avci C, Dogan F, Ozates Ay NP, Goker Bagca B, Abbaszadeh Z and Gunduz C: Effects of telomerase inhibitor on epigenetic chromatin modification enzymes in malignancies. J Cell Biochem 119: 9817-9824, 2018. PMID: 30145821. DOI: 10.1002/jcb.27301

5 Pańczyszyn A, Boniewska-Bernacka E and Głąb G: Telomeres and telomerase during human papillomavirus-induced carcinogenesis. Mol Diagn Ther 22: 421-430. 2018. PMID: 29777397. DOI: 10.1007/s40291-018-0336-x.

6 Ganesan $\mathrm{K}$ and $\mathrm{Xu} \mathrm{B}$ : Telomerase inhibitors from natural products and their anticancer potential. Int J Mol Sci 19: 13, 2017. PMID: 29267203. DOI: 10.3390/ijms19010013

7 Zhang LP, Jiang JK, Tam JW, Zhang Y, Liu XS, Xu XR, Liu BZ and He YJ: Effects of matrine on proliferation and differentiation in K-562 cells. Leuk Res 25: 793-800, 2001. PMID: 11489473. DOI: $10.1016 / \mathrm{S} 0145-2126(00) 00145-4$

8 Ferreira D, Adega $\mathrm{F}$ and Chaves R: The importance of cancer cell lines as in vitro models in cancer methylome analysis and anticancer drugs testing. In: Oncogenomics and Cancer Proteomics - Novel Approaches in Biomarkers Discovery and Therapeutic Targets in Cancer. Lopez-Camarillo C and Arechaga-Ocampo E (eds.). InTech, 2013. DOI: 10.5772/53110

9 Boehm JS and Hahn WC: Immortalized cells as experimental models to study cancer. Cytotechnology 45: 1-2, 2004. PMID: 19003243. DOI: $10.1007 / \mathrm{s} 10616-004-5125-1$

10 Masters JR: Human cancer cell lines: Fact and fantasy. Nat Rev Mol Cell Biol 1: 233, 2000. PMID: 11252900. DOI: 10.1038/ 35043102

11 Ben-David U, Beroukhim R and Golub TR: Genomic evolution of cancer models: Perils and opportunities. Nat Rev Cancer 19(2): $97-$ 109, 2019. PMID: 30578414. DOI: 10.1038/s41568-018-0095-3

12 Rumjanek VM, Trindade GS, Wagner-Souza K, de-Oliverira MC, Marques-Santos LF and Maia RC: Multidrug resistance in tumour cells: Characterisation of the multidrug resistant cell line K562K-562-Lucena1. Anais Acad Bras Ciências 73: 57-69, 2001. PMID: 11246270. DOI: 10.1590/S0001-37652001000100 007
13 Rumjanek VM, Vidal RS and Maia RC: Multidrug resistance in chronic myeloid leukaemia: How much can we learn from MDR-CML cell lines? Biosci Rep 33: 875-888, 2013. PMID: 24070327. DOI: 10.1042/BSR20130067

14 Leal MF, Martins do Nascimento JL, da Silva CE, Vita Lamarão MF, Calcagno DQ, Khayat AS, Assumpção PP, Cabral IR, de Arruda Cardoso Smith M and Burbano RR: Establishment and conventional cytogenetic characterization of three gastric cancer cell lines. Cancer Genet Cytogenet 195: 85-91, 2009. PMID: 19837275. DOI: $10.1016 /$ j.cancergencyto.2009.04.020

15 Nissan MH, Pratilas CA, Jones AM, Ramirez R, Won H, Liu C, Tiwari S, Kong L, Hanrahan AJ, Yao Z, Merghoub T, Ribas A, Chapman PB, Yaeger R, Taylor BS, Schultz N, Berger MF, Rosen N and Solit DB: Loss of NF1 in cutaneous melanoma is associated with RAS activation and MEK dependence. Cancer Res 74: 2340-2350, 2014. PMID: 24576830. DOI: 10.1158/00 08-5472.CAN-13-2625

16 Maués JHDS, Ribeiro HF, Pinto GR, Lopes LO, Lamarão LM, Pessoa CMF, Moreira-Nunes CFA, de Carvalho RM, Assumpção PP, Rey JA and Burbano RMR: Gastric cancer cell lines have different MYC-regulated expression patterns but share a common core of altered genes. Can J Gastroenterol Hepatol 2018: 5804376, 2018. PMID: 30410872 . DOI: $10.1155 / 2018 / 5804376$

17 Lozzio CB and Lozzio BB: Human chronic myelogenous leukemia cell-line with positive Philadelphia chromosome. Blood 45: 321-334, 1975. PMID: 163658.

18 Daflon-Yunes N, Pinto-Silva FE, Vidal RS, Novis BF, Berguetti T, Lopes RR, Polycarpo C and Rumjanek VM: Characterization of a multidrug-resistant chronic myeloid leukemia cell line presenting multiple resistance mechanisms. Mol Cell Biochem 383: 123, 2013. PMID: 23877223. DOI: 10.1007/s11010-013-1761-0.

19 Schmittgen TD and Livak KJ: Analyzing real-time PCR data by the comparative CT method. Nat Prot 3: 1101, 2008. PMID: 18546601 .

20 Bustin SA, Benes V, Garson JA, Hellemans J, Huggett J, Kubista M, Mueller R, Nolan T, Pfaffl MW, Shipley GL, Vandesompele $\mathrm{J}$ and Wittwer CT: The MIQE guidelines: Minimum information for publication of quantitative real-time PCR experiments. Clin Chem 55: 611-622, 2009. PMID: 19246619. DOI: 10.1373/ clinchem.2008.112797

21 Bell RJ, Rube HT, Xavier-Magalhães A, Costa BM, Mancini A, Song, JS and Costello, JF: Understanding TERT promoter mutations: A common path to immortality. Mol Cancer Res 14(4): 315-323, 2016. PMID: 26941407. DOI:10.1158/15417786.MCR-16-0003

22 Okamoto K and Seimiya H: Revisiting telomere shortening in cancer. Cells 8(2): 107, 2019. PMID: 30709063. DOI: 10.3390/ cells 8020107

23 Amisaki M, Tsuchiya H, Sakabe T, Fujiwara Y and Shiota G: Identification of genes involved in the regulation of TERT in hepatocellular carcinoma. Cancer Sci 110(2): 550-560, 2019. PMID: 30447097. DOI: 10.1111/cas.13884

24 Ci X, Li B, Ma X, Kong F, Zheng C, Björkholm M, Jia J and $\mathrm{Xu} \mathrm{D}$ : Bortezomib-mediated down-regulation of telomerase and disruption of telomere homeostasis contributes to apoptosis of malignant cells. Oncotarget 6: 38079, 2015. PMID: 26472030. DOI: $10.18632 /$ oncotarget .5752

25 Shay JW: Role of telomeres and telomerase in aging and cancer. Cancer discovery 6: 584-593, 2016. PMID: 27029895. DOI: 10.1158/2159-8290.CD-16-0062 
26 Lansdorp PM: Maintenance of telomere length in AML. Blood Adv 1: 2467-2472, 2017. PMID: 29296896. DOI: 10.1182/ bloodadvances.2017012112

27 Capraro V, Zane L, Poncet D, Perol D, Galia P, Preudhomme C, Bonnefoy-Berard N, Gilson E, Thomas X, El-Hamri M, Chelghoun Y, Michallet M, Wattel E, Mortreux F and Sibon D: Telomere deregulations possess cytogenetic, phenotype, and prognostic specificities in acute leukemias. Exp Hematol 39: 195-204, 2011. PMID: 21056083. DOI: 10.1016/j.exphem.2010. 10.008

28 Bruedigam $\mathrm{C}$ and Lane SW: Telomerase in hematologic malignancies. Curr Opin Hematol 23: 346-353, 2016. PMID: 27213497. DOI: $10.1097 / \mathrm{MOH} .0000000000000252$

29 Laurén P: The two histological main types of gastric carcinoma: diffuse and so-called intestinal-type carcinoma. An attempt at a histo-clinical classification. Acta Pathol Microbiol Scand 64: 3149, 1965. PMID: 14320675. DOI: 10.1111/apm.1965.64.1.31

30 Choi BJ, Yoon JH, Kim O, Choi WS, Nam SW, Lee JY and Park WS: Influence of the hTERT rs 2736100 polymorphism on telomere length in gastric cancer. World J Gastroenterol 21: 9328, 2015. PMID: 26309358. DOI: 10.3748/wjg.v21.i31.9328

31 Wu X, Chen VW, Ruiz B, Andrews P, Su LJ, and Correa P: Incidence of esophageal and gastric carcinomas among American Asians/Pacific Islanders, Whites, and Blacks: Subsite and histology differences. Cancer 106: 683-692, 2006. PMID: 16388522. DOI: $10.1002 / \mathrm{cncr} .21542$

32 Tang B, Xie R, Qin Y, Xiao YF, Yong X, Zheng L, Dong H and Yang SM: Human telomerase reverse transcriptase (hTERT) promotes gastric cancer invasion through cooperating with $\mathrm{c}$ Myc to up-regulate heparinase expression. Oncotarget 7: 11364, 2016. PMID: 26689987. DOI: 10.18632/oncotarget.6575

33 Hannen R and Bartsch JW: Essential roles of telomerase reverse transcriptase hTERT in cancer stemness and metastasis. FEBS Lett 592: 2023-2031, 2018. PMID: 29749098. DOI: 10.1002/ 1873-3468.13084
34 Wang X, Sun L, Wang X, Kang H, Ma X, Wang M, Lin S, Liu M, Dai $\mathrm{C}$ and Dai $\mathrm{Z}$ : Acidified bile acids enhance tumor progression and telomerase activity of gastric cancer in mice dependent on c-MYC expression. Cancer Med 6: 788-797, 2017. PMID: 28247570. DOI: 10.1002/cam4.999

35 Wang X, Zhou P, Sun X, Zheng J, Wei G, Zhang L, Wang H, Yao J, Lu S and Jia P: Acidified bile acids increase hTERT expression via c-MYC activation in human gastric cancer cells. Oncol Rep 33: 3038-3044, 2015. PMID: 25873431. DOI: 10.3892/or.2015.3908

36 Viceconte N, Dheur MS, Majerova E, Pierreux CE, Baurain JF, van Baren $\mathrm{N}$ and Decottignies A: Highly aggressive metastatic melanoma cells unable to maintain telomere length. Cell Rep 19: 2529-2543, 2017. PMID: 28636941. DOI: 10.1016/j.celrep. 2017.05.046

37 Kishtagari A and Watts J: Biological and clinical implications of telomere dysfunction in myeloid malignancies. Therapeut Adv Hematol 8: 317-326, 2017. PMID: 29093807. DOI: 10.1177/ 2040620717731549

38 Wysoczanska B, Dratwa M, Gebura K, Mizgala J, Mazur G, Wrobel $\mathrm{T}$ and Bogunia-Kubik K: Variability within the human TERT gene, telomere length and predisposition to chronic lymphocytic leukemia. OncoTargets Ther 12: 4309, 2019. PMID: 31239704. DOI: 10.2147/OTT.S198313

39 Ludlow AT, Slusher AL and Sayed ME: Insights into telomerase/hTERT alternative splicing regulation using bioinformatics and network analysis in cancer. Cancers 11(5): 666, 2019. PMID: 31091669. DOI: 10.3390/cancers11050666

Received July 16, 2019

Revised July 24, 2019

Accepted July 30, 2019 